Document downloaded from:

http://hdl.handle.net/10251/103134

This paper must be cited as:

Díaz Calleja, R.; Sanchis Sánchez, MJ.; Gargallo, L.; Radic, D. (1996). Viscoelastic relaxation phenomena in poly(mono-n-alkyl itaconates). Journal of Polymer Science Part B Polymer Physics. 34(2):261-266. doi:10.1002/(SICI)1099-0488(19960130)34:2<261::AIDPOLB6>3.0.CO;2-W

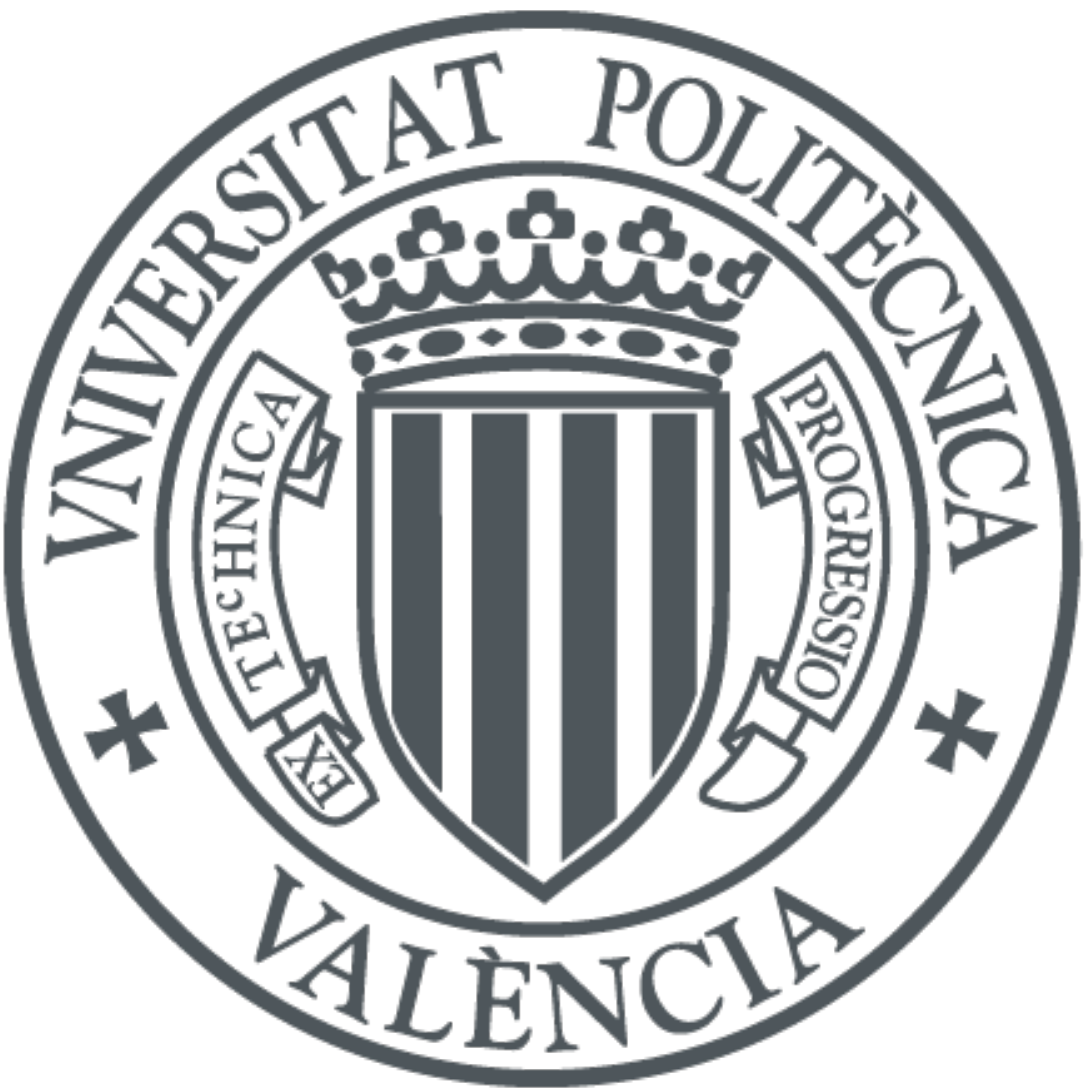

The final publication is available at

https://doi.org/10.1002/(SICI)1099-0488(19960130)34:2<261::AID-POLB6>3.0.CO;2-W

Copyright John Wiley \& Sons

Additional Information 


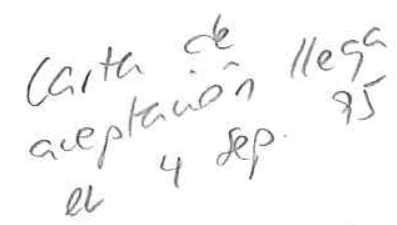

\title{
VISCOELASTIC RELAXATION PHENOMENA IN POLY(MONO-n-ALKYL ITACONATES)
}

\author{
R. Díaz Calleja*a), M.J. Sanchisa), L. Gargallob) and D. Radic'b). \\ a)Depto. Termodinámica Aplicada, E.T.S.I.I. Universidad Politecnica de Valencia, \\ Valencia, Spain. \\ b)Depto. Química Fisica, Facultad de Química, Pontificia Universidad Católica de \\ Chile Casilla 306, Santiago 22, Chile
}

\section{SYNOPSIS}

Dynamic mechanical relaxation measurements have been carried out on two poly(monoalkylitaconates). Three relaxation peaks between $-120^{\circ} \mathrm{C}$ and $140^{\circ} \mathrm{C}$ are present. A prominent subglass relaxation $(\beta)$ near $-60^{\circ} \mathrm{C}$ have been studied by means of the Fuoss-Kirkwood formalism. A slight viscoelastic activity $\left(\beta^{\prime}\right)$ is observed at room temperature, and then a high temperature peak $(\alpha)$ probably related to the glass transition is found. These phenomena have not been detected before by D.S.C. A biparabolic model, double Cole constant phase element has been used to modelize the experimental data in this zone.

\section{INTRODUCTION}

In a previous paper ${ }^{1}$, the dielectric relaxation phenomena for a family of poly(n-alkyl itaconates) i.e. poly(monooctyl itaconate) [poly(1-carboxy-1octyloxycarbonylmethylethylene)] (PMOI), poly(monodecyl itaconate) [poly(1carboxy-1-decyloxycarbonylmethylethylene)] (PMDI), poly(monododecyl itaconate) [poly(1-carboxy-1-dodecyloxycarbonylmethylethylene)] (PMDol) and poly(monotetradecyl itaconate) [poly(1-carboxy-1-tetradecyloxycarbonylmethyl ethylene)] (PMTDI) were studied. Two relaxation phenomena were reported for each one of the four polymers studied. One of them ( $\gamma$ relaxation) around $-120^{\circ} \mathrm{C}$ 
$0.2,0.3,1,2,3,5,10,20$ and $30 \mathrm{~Hz}$ ) were performed at intervals from about 5 to $7^{\circ} \mathrm{C}$. This type of measurements need larger times but they take advantage in the sense that more accurate results are obtained. The stabilization time temperature was $8 \mathrm{~min}$. Because of the small dimensions of the sample we considered that the time is enough to reach a good stabilization of the temperature in the probes.

\section{RESULTS AND DISCUSSION}

Figures 1 and 2 show the storage and loss modulus for both polymers at three frequencies $(0.1,1$ and $10 \mathrm{~Hz})$ in the temperature range studied. A similar viscoelastic response is observed in both polymers. About $60^{\circ} \mathrm{C}(1 \mathrm{~Hz})$ a prominent and broad relaxation is observed. A weak relaxation phenomena seem to be present near room temperature. At $108^{\circ} \mathrm{C}$ and $123^{\circ} \mathrm{C}(1 \mathrm{~Hz})$ was possible to observe, for PMOI and PMDI respectively, similar peaks to that observed for amorphous polymers near the glass transition temperature.

The activation energies were calculated from the $\mathrm{Ln} \mathrm{fm}_{\mathrm{m}} \mathrm{vs} \mathrm{T}^{-1}$ by the Arrhenius method; for the relaxations at lower temperatures that we labelled as $\beta$ relaxation are $25 \mathrm{kcal} \mathrm{mol}^{-1}$ in both cases. The relaxation nearly room temperature which is labelled as $\beta^{\prime}$ is also a broad and diffuse phenomenun and therefore it is not possible to determine reliable values for the activation energy. On the contrary, absorptions at higher temperatures are well defined processes and in both cases the energy of activation values of 120 and $140 \mathrm{kcal} \mathrm{mol}^{-1}$ are obtained.

According to the values of the activation energy obtained for the $\beta$ relaxation and the position of the peaks it is possible to guess that the origin of this relaxation is similar to that of the $\beta$ relaxation detected by dielectric measurements. In order to study in a more detailed way this process, the master curves for the loss modulus of both polymers were constructed in the relaxation zone and reduced to $-70^{\circ} \mathrm{C}$. See Figure 3 where many experimental points are amitted for clarity. A small scattering is observed at high temperatures because of 
the presence of the $\beta^{\prime}$ peak. In order to represent the experimental data, the Fuoss-Kirkwood ${ }^{9}$ equation was used as an empirical model:

$$
E^{\prime \prime}=E^{\prime \prime} \max \operatorname{sech} m \operatorname{Ln} \frac{f_{m}}{f}
$$

and using the equation taken from reference (10):

$$
2 E^{\prime \prime} \max =m \Delta E
$$

the strength of the relaxation $\Delta \mathrm{E}$ was estimated. In order to obtain the absolute values of $E_{o}$ and $E_{\infty}$ and considering the simmetry of the $\beta$ relaxation it is posible to assume:

$$
E_{m}^{\prime}=\frac{1}{2}\left(E_{0}+E_{\infty}\right)
$$

where $E^{\prime} m$ is is the storage modulus value at $1 \mathrm{~Hz}$ at constant frequency and at the temperature where $\quad E^{\prime \prime}=E^{\prime \prime} \max$. From $\Delta E=E_{O}-E_{\infty}$ where $\Delta E$ is known from eq. 2 we can easily calculate $E_{0}$ and $E_{\infty}$. Table 1 summarizes the values obtained for all these parameters. It is noteworthy the high values of the relaxation intensity for both polymers. Similar behaviour is observed for the corresponding $\beta$ dielectric relaxations ${ }^{1}$. This behaviour is indicative that not only are polar groups but also there is a contribution of the main chain. In a tentative way it can be proposed that the side groups, in a cooperative way with the main chain are the responsible of the $\beta$ relaxation of poly(cyclohexyl itaconate) ${ }^{2}$. On the other hand, the values of the $m$ parameter, which represent the broadening of the relaxation, are slightly lower in the case of viscoelastic than in dielectric relaxations, being these last values 0.16 and 0.20 for PMOI and PMDI respectively.

It is well known the asymmetric character of the relaxations associated to the glass transition temperature. Figure 4 shows E" against E' for PMDI at $120^{\circ} \mathrm{C}$. Master curves for $E^{\prime}$ and $E^{\prime \prime}$ can be constructed in the same way as for the $\beta$ 
relaxation. The scattering observed at high frequencies can be attributed to the $\beta^{\prime}$ process and therefore the five last experimental points are not considering for the subsequent fitting. In a previous paper ${ }^{11}$ the biparabolic model ${ }^{12}$ for the representation of the data in the relaxation zone was proposed according to the following equation:

$$
E^{*}=E_{O+} \frac{E_{\infty}-E_{0}}{1+\delta(j w \tau)^{-h}+(j w \tau)^{-k}}
$$

where $E_{0}$ and $E_{\infty}$ represent the relaxed and non-relaxed modulus respectively and $\mathrm{h}, \mathrm{k}$ and $\delta$ are empirical parameters where:

$$
\mathrm{h}=\frac{2}{\pi} \varphi \quad \text { and } \quad \mathrm{k}=\frac{2}{\pi} \psi
$$

being $\varphi$ and $\psi$ the angles formed by the skewed arcs with the horizontal axis at zero and infinite frequency respectively and $\tau$ is the characteristic relaxation time. Biparabolic model can be encouraged as a generalization of the Cole-Cole equation ${ }^{13}$, containing two constant phase elements (CPE) defined by (jwr)-a. The two different exponents of each CPE introduce asymmetry in the mode. On the other hand the analogous viscoelastic equation proposed by Havriliak and Negami ${ }^{14}$ to represent the dielectric dispersion in polymers is:

$$
D^{*}=D_{\infty}+\frac{D_{0}-D_{\infty}}{\left(1+(j w \tau)^{\alpha}\right)^{\beta}}
$$

where $D^{*}$ is the dynamic compliance and $D_{0}$ and $D_{\infty}$ are the compliance at zero and infinite frequency respectively. As the complex modulus is the inverse of the complex compliance equation (6) can be written as:

$$
E^{*}=\frac{E_{\infty}}{1+\frac{E_{\infty}}{E_{O}}\left(1+(j w \tau)^{\alpha}\right)^{-\beta}}
$$


where $E_{\infty}=D_{\infty}{ }^{-1}$ and $E_{0}=D_{0}{ }^{-1}$.

The obtained errors analysing the experimental results from equation (7) are considerably larger than applying equation (4). This situation can be attributed to the fact that the term $\frac{E_{\infty}}{E_{0}}$ which appears in the denominator of equation $(7)$ is not very accurate because the $E_{0}$ value is near the limit of accurate measurements in DMTA. On the other hand the relationships among the parameters of equations (4) and (7) are:

$$
\mathrm{h}=\alpha \quad \text { and } \quad \mathrm{k}=\alpha \beta
$$

In the case of equation (4) the poblems above mentioned are less relevants because $\mathrm{E}_{\infty} \gg \mathrm{E}_{0}$, therefore the equation can be written:

$$
E^{\star}=\frac{E_{\infty}}{1+\delta(j w \tau)^{-h}+(j w \tau)^{-k}}
$$

The treatment of the experimental data in this case start constructing the master curves for E' and E" at a determined temperature of reference. It has been used the Complex Nonlinear Least Squares Immitance Fitting Program LEVM6 of $\mathrm{J}$. Ross MacDonald in order to fit the biparabolic model to the experimental data in the zone corresponding to this relaxation. The equivalent electric circuit and the experimental parameters corresponding to equation (9) are shown in Figure 5 and Table II. In order to verify the goodnes of the fit a residual Table for $\varepsilon$ " is given (Table 3 ) for each polymer. As can be seen a very good fit is obtained.

The homologous mechanical model corresponding to the above circuit is shown in Figure 6 . In this circuit the paralel elastic element which corresponds to the modulus completely relaxed has been omited because its value is not important compared with the other parameters of the scheme. This electric circuit would correspond to a complex compliance given by the inverse of equation (9): 


$$
D^{*}=D \infty\left(1+\delta(j w \tau)^{-h}+(j w \tau)^{-k}\right)
$$

with $\mathrm{D}_{\infty}=\mathrm{E}_{\infty}{ }^{-1}$

\section{CONCLUSIONS}

Two new relaxations has been observed at higher temperatures than that for the former dielectric measurements in PMOI and PMDI. One of them can be assignated to the classical glass transition in both polymers. By using a fitting procedure previously applied to dielectric measurements a biparabolic model is found. This model allows us in a reasonable degree of accuracy in the fitting process.

Acknowledgements: L.G. and D.R. express their thanks to FONDECYT and DIUC for partial financial support. 


\section{REFERENCES}

1. A. Ribes-Greus, R. Díaz Calleja, L. Gargallo and D. Radic', Polymer, 32 , 2755 (1991)

2. R. Díaz Calleja, E. Saiz, E. Riande, L. Gargallo and D. Radic' J. Polym. Sci., Phys. Ed. 32,1069 (1994)

3. R. Díaz Calleja, L. Gargallo and D. Radic', J. Appl. Polym. Sci.,46, 393 (1992)

4. J.M.G. Cowie and Z. Haq, Br. Polym., J., 2,241 (1977)

5. R. Díaz Calleja, A. Ribes Greus, L. Gargallo and D. Radic', Polym. Int., 25 , 51 (1991)

6. L. Gargallo, D. Radic'and A. León, Makromol. Chem., 1 86, 1289 (1985)

7. A. León, L. Gargallo, A. Horta and D. Radic', J. Polym. Sci., Polym. Phys. Ed., A, 2337 (1989)

8. A. León, L. Gargallo, D. Radic'and A. Horta Polymer, 32, 761 (1991)

9. R. Fuoss, J.G. Kirkwood, J. Am. Chem. Soc., 63, 385 (1941)

10. N.G.Mc Crum, B.E. Read, G. Williams, Anelastic and Dielectric effects in Polymeric Solids, Wiley and Sons, N. Y. 1967.

11. R. Díaz Calleja, E. Riande, J. San Román, Macromolecules 24,1854 (1991)

12. J.Y. Decroix, A. Piloz, A. Douillard, J.F. May and G. Vallet, Eur. Polym. J. 11, 625 (1975)

13. K.S. Cole, K.K. Cole, J. Chem. Phys., 9, 341 (1941)

14. S. Havriliak and S. Negami Polymer, 8, 161 (1967) 
TABLE 1. Values of the parameters appearing in equations (2) and (3) corresponding to the $\beta$ relaxation for $\mathrm{PMOI}$ and PMDI.

\begin{tabular}{lcccl} 
& $\mathrm{m}$ & $\Delta \mathrm{E}(\mathrm{Pa})$ & $\mathrm{E}_{0}(\mathrm{~Pa})$ & $\mathrm{E}_{\infty}(\mathrm{PA})$ \\
\hline PMOI & 0.143 & $1.65 \cdot 10^{9}$ & $2.46 \cdot 10^{9}$ & $8.12 \cdot 10^{8}$ \\
PMDI & 0.157 & $1.66 \cdot 10^{9}$ & $2.44 \cdot 10^{9}$ & $7.81 \cdot 10^{8}$ \\
\hline
\end{tabular}


TABLE 2. Parameters corresponding to equation (9) and Figure 5

$\mathrm{z}_{1}^{*} \mathrm{z}_{2}^{*} \quad \mathrm{z}_{3}^{*}$

PMOI $\left(j w \cdot 1.14 \cdot 10^{-9}\right)^{-1} \quad\left(0.1881 \cdot 10^{-9}(j w)^{0.4674}\right)^{-1} \quad\left(0.1802 \cdot 10^{-9}(j w)^{0.7856}\right)^{-1}$

PMDI (jw . 1.05 $\left.\cdot 10^{-9}\right)^{-1} \quad\left(0.7762 \cdot 10^{-11}(j w)^{0.3074}\right)^{-1} \quad\left(0.7184 \cdot 10^{-9}(j w)^{0.7488}\right)^{-1}$
$\Delta \mathrm{E}(\mathrm{Pa})$
h
k
$\delta$
$\tau(\mathrm{s})$

PMOI $\quad 0.88 \cdot 10^{9} \quad 0.5326$

0.2144

0.053

0.1170

PMDI $0.95 \cdot 10^{9} \quad 0.6$ 
Table 3. Residuals for the imaginary part of the complex modulus for PMOI and PMDI, measured values obtained from master curves, estimated are calculated from the model using parameters of Table 2.

\begin{tabular}{cccc}
\hline $\log f(\mathrm{~Hz})$ & Measured & Estimated & Resid/Model \\
\hline & & & \\
PMOI & & & \\
-3.5 & $2.40000 \mathrm{E}+07$ & $2.33330 \mathrm{E}+07$ & $2.85862 \mathrm{E}-02$ \\
-3.0 & $3.10000 \mathrm{E}+07$ & $3.23711 \mathrm{E}+07$ & $-4.23571 \mathrm{E}-02$ \\
-2.5 & $4.30000 \mathrm{E}+07$ & $4.22573 \mathrm{E}+07$ & $1.75759 \mathrm{E}-02$ \\
-2.0 & $5.25000 \mathrm{E}+07$ & $5.21056 \mathrm{E}+07$ & $7.56860 \mathrm{E}-03$ \\
-1.5 & $6.10000 \mathrm{E}+07$ & $6.11294 \mathrm{E}+07$ & $-2.11711 \mathrm{E}-03$ \\
-1.0 & $6.90000 \mathrm{E}+07$ & $6.87721 \mathrm{E}+07$ & $3.31405 \mathrm{E}-03$ \\
-0.5 & $7.55000 \mathrm{E}+07$ & $7.46641 \mathrm{E}+07$ & $1.11949 \mathrm{E}-02$ \\
0.0 & $7.85000 \mathrm{E}+07$ & $7.85361 \mathrm{E}+07$ & $-4.59028 \mathrm{E}-04$ \\
0.5 & $8.00000 \mathrm{E}+07$ & $8.01918 \mathrm{E}+07$ & $-2.39218 \mathrm{E}-03$ \\
1.0 & $7.95000 \mathrm{E}+07$ & $7.95508 \mathrm{E}+07$ & $-6.39142 \mathrm{E}-04$ \\
1.5 & $7.70000 \mathrm{E}+07$ & $7.67068 \mathrm{E}+07$ & $3.82205 \mathrm{E}-03$ \\
& & & \\
PMDI & & & \\
-3.5 & $3.40800 \mathrm{E}+07$ & $3.35983 \mathrm{E}+07$ & $1.43385 \mathrm{E}-02$ \\
-3.0 & $4.70000 \mathrm{E}+07$ & $4.73534 \mathrm{E}+07$ & $-7.46331 \mathrm{E}-03$ \\
-2.5 & $6.00000 \mathrm{E}+07$ & $6.04510 \mathrm{E}+07$ & $-746122 \mathrm{E}-03$ \\
-2.0 & $7.25000 \mathrm{E}+07$ & $7.19158 \mathrm{E}+07$ & $8.12356 \mathrm{E}-03$ \\
-1.5 & $8.25000 \mathrm{E}+07$ & $8.16938 \mathrm{E}+07$ & $9.86869 \mathrm{E}-03$ \\
-1.0 & $9.10000 \mathrm{E}+07$ & $8.97232 \mathrm{E}+07$ & $1.42303 \mathrm{E}-02$ \\
-0.5 & $9.55000 \mathrm{E}+07$ & $9.55158 \mathrm{E}+07$ & $-1.65445 \mathrm{E}-04$ \\
0.0 & $9.75000 \mathrm{E}+07$ & $9.83349 \mathrm{E}+07$ & $-8.49017 \mathrm{E}-03$ \\
1.0 & $9.25000 \mathrm{E}+07$ & $9.32218 \mathrm{E}+07$ & $-7.74259 \mathrm{E}-03$ \\
1.5 & $8.80000 \mathrm{E}+07$ & $8.57074 \mathrm{E}+07$ & $2.67493 \mathrm{E}-02$ \\
\hline & & & \\
\hline
\end{tabular}




\section{FIGURE CAPTIONS}

Figure 1. Storage and loss moduli for PMOI as function of temperature at $0.1(\bullet), 1(\mathrm{x})$ and $10(\boldsymbol{w}) \mathrm{Hz}$.

Figure 2. Storage and loss moduli for PMDI as function of temperature at $0.1(\bullet), 1(x)$ and $10(v) \mathrm{Hz}$.

Figure 3. Reduced master curves at $-70^{\circ} \mathrm{C}$ for the $\beta$ relaxation of $\mathrm{PMOI}$ (top): $-120^{\circ} \mathrm{C}$ $(\bullet),-110^{\circ} \mathrm{C}(\mathrm{x})-100(\nabla),-90(\Delta),-80(0),-70(\mathrm{O}),-60(+),-50(\mathrm{O}),-40(\square)$ and PMDI (botton): $-110(\bullet),-100(+),-90(\nabla),-80(\Delta),-70(x),-60(0),-50(0),-40(0),-30(\square)$.

Figure 4. Cole-Cole arc for the $\alpha$ relaxation of PMDI at $120^{\circ} \mathrm{C}$

Figure 5. Equivalent electric circuit to the equation (9).

Figure 6. Homologous mechanical model corresponding to the circuit of Figure 5. Symbols below the figure correspond to the equation (9) 


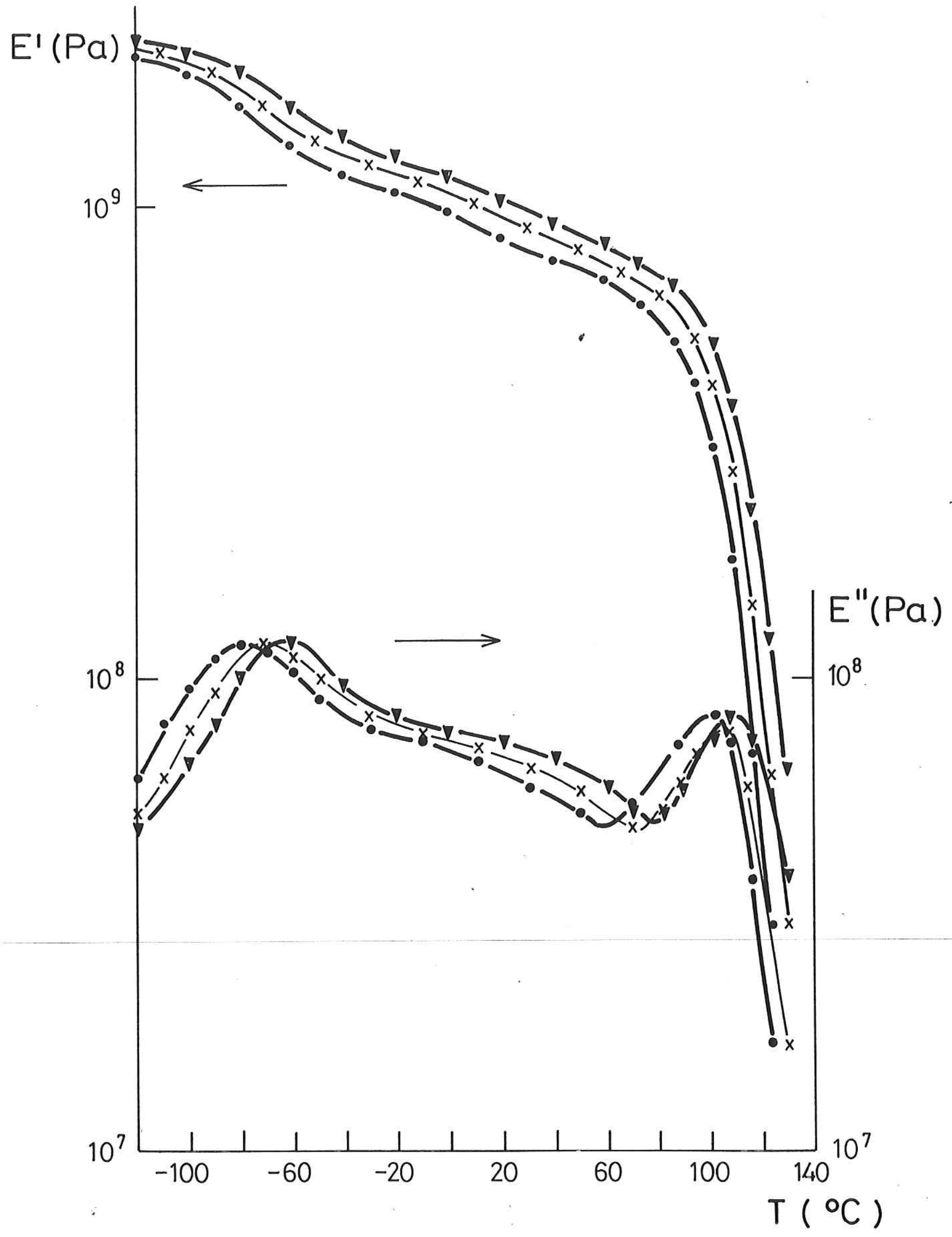




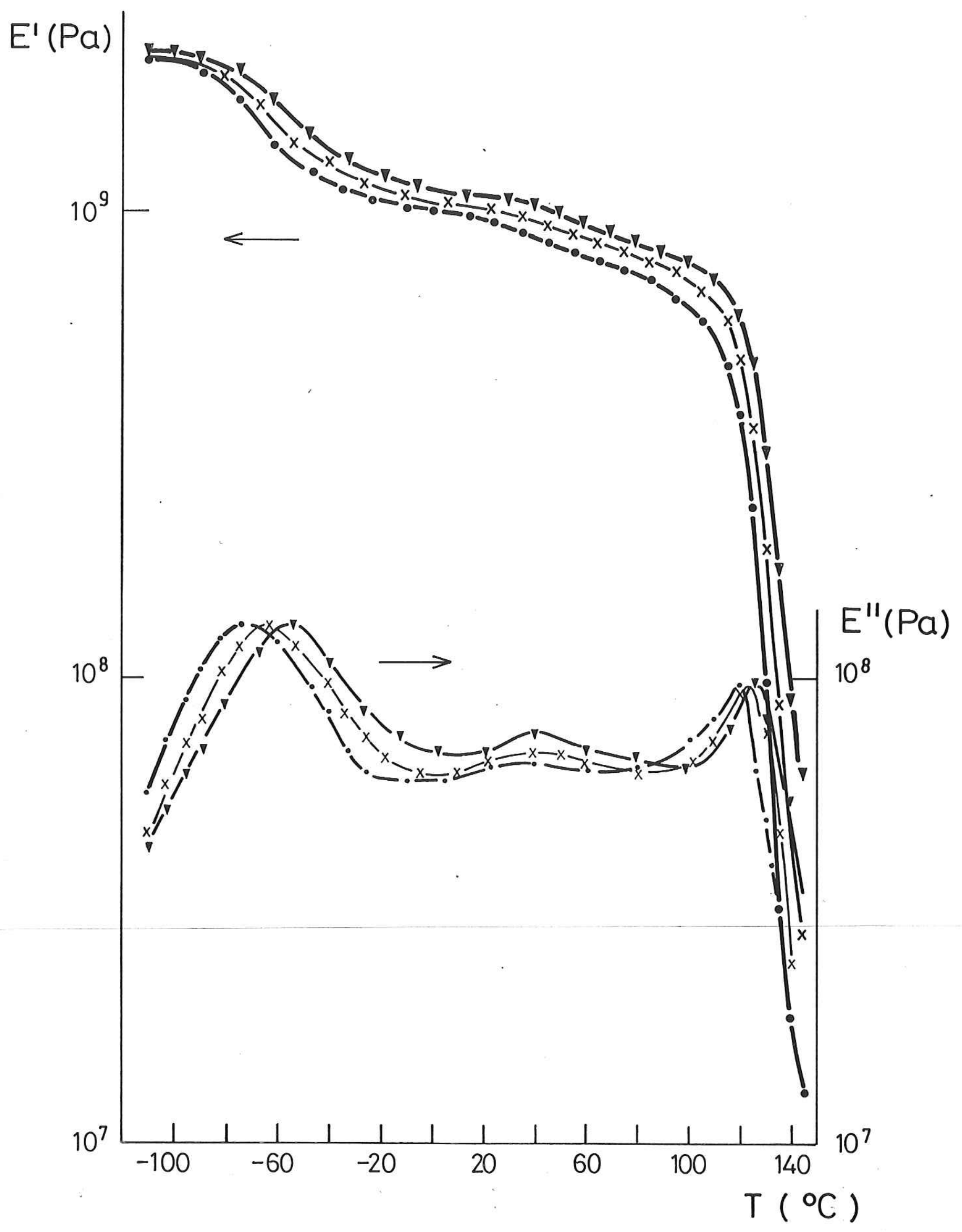


Feg
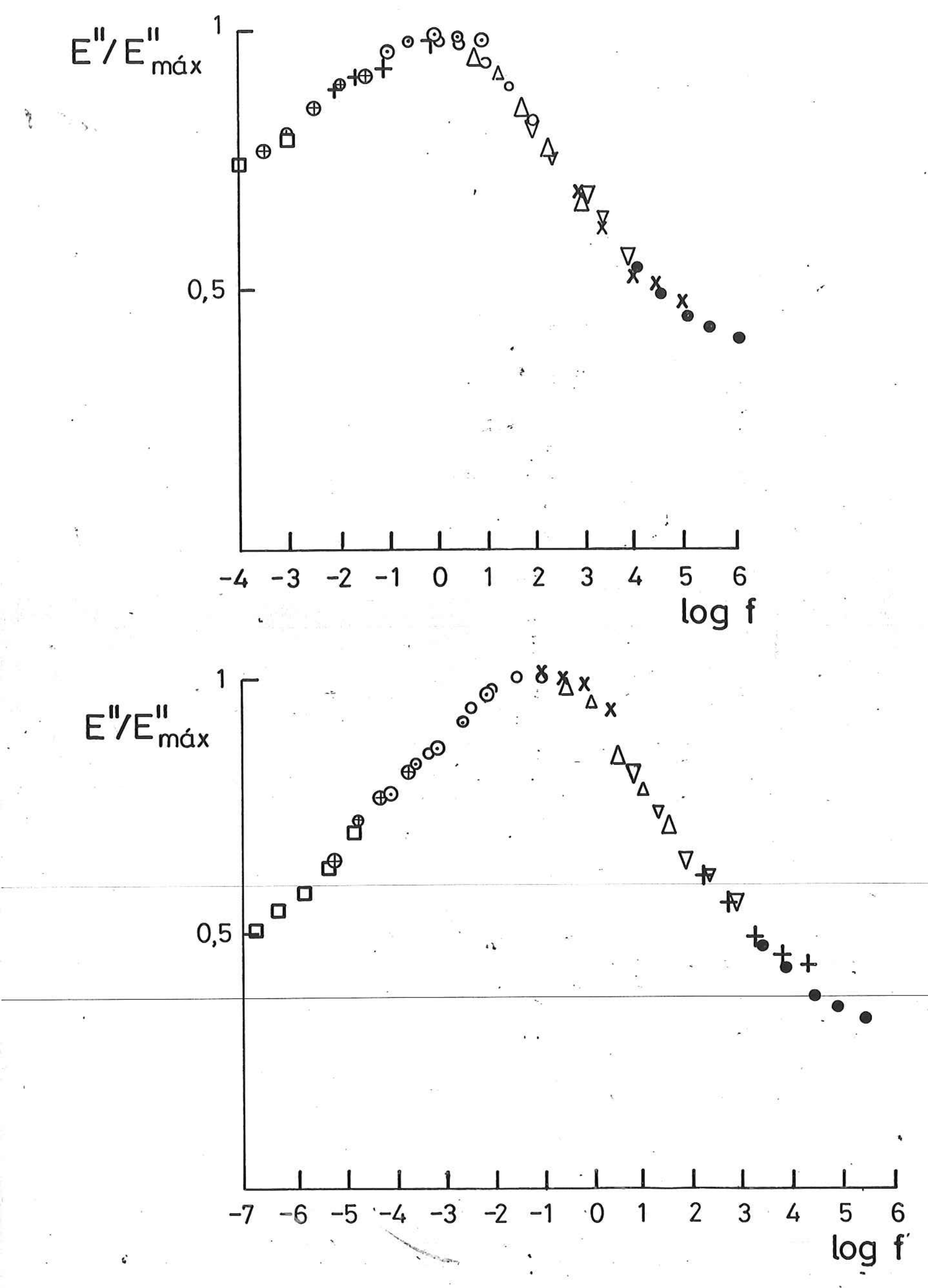


$$
r_{q} \cdot 4
$$

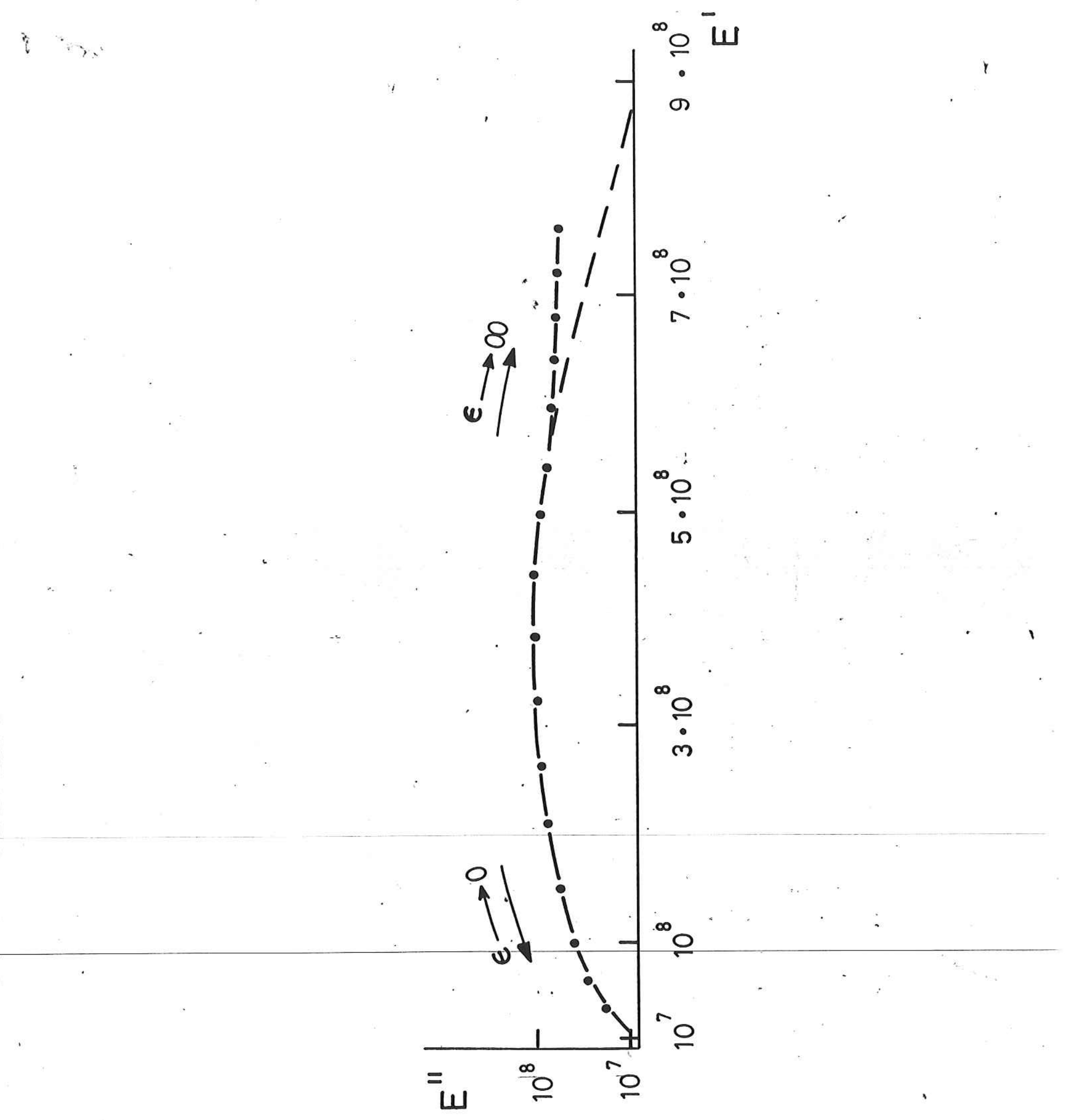




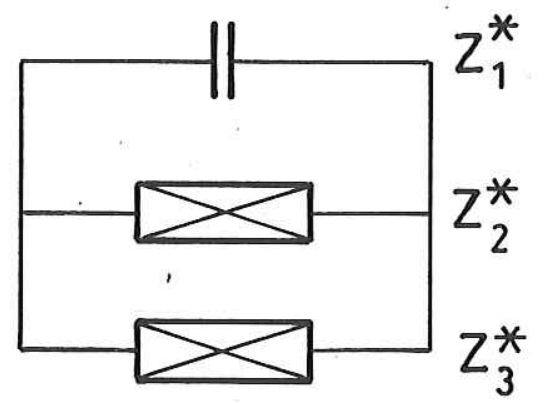

Fiquas

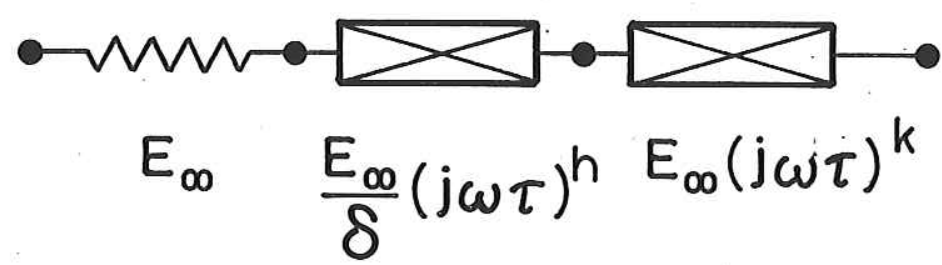

Figune 6 